\title{
Anti-fibrotic effects of specific-siRNA targeting of the receptor for advanced glycation end products in a rat model of experimental hepatic fibrosis
}

\author{
XIAO-GANG CAI，JIN-RONG XIA，WEI-DONG LI，FENG-LIN LU，JUAN LIU, QIN LU and HONG ZHI
}

Department of Gastroenterology, Zhongda Hospital, School of Medicine, Southeast University, Nanjing, Jiangsu 210009, P.R. China

Received September 23, 2013; Accepted March 18, 2014

DOI: $10.3892 / \mathrm{mmr} .2014 .2207$

\begin{abstract}
Since the receptor for advanced glycation end products (RAGE)-ligand axis has been demonstrated to be important in fibrogenesis, rat models may be used to assess whether specific small interfering RNAs (siRNAs) that target RAGE are able to reduce the progression of hepatic fibrosis. However, the effect of RAGE-targeted siRNA on established hepatic fibrosis remains to be elucidated. In the present study, RAGE-specific siRNA expression vectors were constructed prior to the animal experiment. Sprague-Dawley rats were treated initially with olive oil $(2 \mathrm{ml} / \mathrm{kg})$ or $50 \% \mathrm{CCl}_{4}(2 \mathrm{ml} / \mathrm{kg}$; $\mathrm{CCl}_{4} /$ olive oil=1:1) twice per week for six weeks to generate the fibrosis model. The rats were then treated with phosphate-buffered saline, a RAGE-specific siRNA expression vector, at different doses or a non-specific siRNA expression vector twice weekly via tail vein injection for up to six weeks, and were sacrificed at week two, four or six. Compared with the control groups, RAGE-specific siRNA therapy significantly decreased RAGE mRNA and protein expression in rat livers $(\mathrm{P}<0.01)$. Following six weeks of RAGE gene-silencing treatment, the liver function, which was assessed by analyzing serum levels of alanine aminotransferase (ALT), aspartate aminotransferase (AST), alkaline phosphatase (ALP) and total bilirubin (TBIL), improved to varying degrees $(\mathrm{P}<0.01)$. The expression of nuclear factor- $\kappa \mathrm{B}(\mathrm{NF}-\kappa \mathrm{B})$ significantly decreased following RAGE gene-silencing therapy $(\mathrm{P}<0.01)$. In addition, the serum levels of inflammatory cytokines, including tumor necrosis factor- $\alpha(\mathrm{TNF}-\alpha)$ and interleukin- 6 (IL-6), and extracellular matrix (ECM) components, including hyaluronic acid (HA), laminin (LN) and procollagen type III (PCIII) also decreased $(\mathrm{P}<0.01)$. Furthermore, the expression of $\alpha$-smooth muscle actin ( $\alpha$-SMA) and collagen I, which indicate the activation of hepatic stellate cells (HSCs), were
\end{abstract}

Correspondence to: Professor Jin-Rong Xia, Department of Gastroenterology, Zhongda Hospital, School of Medicine, Southeast University, No. 87 Dingjiaqiao Road, Nanjing, Jiangsu 210009, P.R. China

E-mail: xjr049540@163.com

Key words: small interfering RNA, receptor for advanced glycation end products, hepatic fibrosis downregulated following RAGE gene-silencing therapy $(\mathrm{P}<0.01)$. Furthermore, the inflammatory activity grade and fibrosis stage of rat livers also significantly improved compared with the control groups following RAGE gene-silencing therapy. Specific targeting of RAGE using siRNA may inhibit RAGE gene expression effectively in the rat hepatic fibrosis model and attenuate the progression of established hepatic fibrosis. This therapeutic effect may be mediated via inhibition of the expression of NF- $\kappa \mathrm{B}$. These findings suggest that RAGE may be a new target to prevent hepatic fibrosis.

\section{Introduction}

Liver cirrhosis, which is the end stage of several types of liver disease, is a global problem due to a lack of efficient therapies. Hepatic fibrosis is a necessary step in the development of liver cirrhosis. Therefore, the prevention and reversal of fibrosis is of high priority. Hepatic fibrosis is a pathological process that involves the deposition of extracellular matrix (ECM) (1) due to wound healing that is initiated in response to continuous injuries to liver tissue. Hepatic stellate cells (HSCs), which are located in the subendothelial space of Disse between hepatocytes and sinusoidal endothelial cells, have been identified as a major cellular source of ECM in liver injury, and the activation of HSCs is regarded as central to the pathogenesis of hepatic fibrosis (2-4). When the liver suffers injuries, inflammatory cells, injured hepatocytes and bile duct cells may generate or secrete substances that initiate the activation of HSCs, including cytokines, reactive oxygen species and nitric oxide. During this activation process, HSCs undergo phenotype transformation from vitamin-A-storing quiescent cells to myofibroblasts and autocrine and paracrine stimulation may enhance this activation. Subsequently, the robust increase in collagen synthesis that occurs leads to the accumulation of ECM and thus hepatic fibrosis (5).

The receptor for advanced glycation end products (RAGE) is a member of the immunoglobulin super family of receptors (6). RAGE is a multiligand receptor and its ligands include advanced glycation end products, high mobility group family proteins, members of the S100/calgranulin proinflammatory cytokine family, $\beta$-amyloid peptide and other ligands $(7,8)$. The binding of these ligands to RAGE results in the generation of intracellular oxidative stress and subsequent activation of the transcription factor nuclear factor- $\kappa \mathrm{B}(\mathrm{NF}-\kappa \mathrm{B})(9,10)$. 
In addition, interaction of RAGE with these ligands enhances receptor expression and initiates a positive feedback loop that results in sustained RAGE upregulation (11).

RAGE is expressed in a broad range of cell types, including cardiomyocytes, vascular cells and inflammatory cells and, thus, is observed in HSCs $(11,12)$. Several studies have demonstrated that hepatic RAGE expression is increased in animal models of chronic liver disease and liver cirrhosis. In a rat model of liver fibrosis, which is induced by bile duct ligation or thioacetamide treatment, the RAGE transcript is markedly upregulated (13). In addition, a number of studies have demonstrated that RAGE expression is upregulated during the transdifferentiation and subsequent migration of HSCs to myofibroblasts (14). A previous study by our group demonstrated that RAGE gene silencing effectively prevented liver fibrosis (15). In the present study, to assess the therapeutic effects of RAGE gene silencing on hepatic fibrosis and to investigate the mechanistic details, the effects of specific RAGE-targeted small interfering RNA (siRNA) on the carbon tetrachloride $\left(\mathrm{CCl}_{4}\right)$-induced rat model of hepatic fibrosis were investigated.

\section{Materials and methods}

Preparation of specific RAGE-targeted siRNA. Rat RAGE mRNA (GeneBank number, NM-053336.1) was used as the target sequence. RNA-designing software (https://rnaidesigner. lifetechnologies.com/rnaiexpress/setOption.do?designOption=s irna\&pid $=8819012764449116449)$ was used to model the secondary structures of rat RAGE mRNA. In total, five pairs of 19 nt siRNA sequences were designed based on the target sequence and its complementary sequence (specificity of sequences were confirmed using BLAST). They were then converted into short RNA oligonucleotide sequences that formed hairpin structures. BglII and $K p n I$ restriction enzyme sites and a 9-bp loop, which forms the hairpin structure, were added to the two terminuses of the sequences. The final oligonucleotides were named GR125, GR126, GR127, GR128 and GR129. The siRNA sequences used were: GR125 (targeting RAGE mRNA 151-169) forward, 5'-GATCCCCGCCAACCCA GAAGCTAGAATTCAAGAGATCTAGCTTCTGG GTTGG CTTTTTTGTA-3' and reverse, 5'-AAAAAAGCCAACCCAG AAGCTAGAA CTCTTGAATTCTAGCTTCTGGGTTGGC GGG-3'; GR126 (targeting RAGE mRNA 394-412) forward, 5'-GATCCCCGTGAATCCTGCCTCTGAAC TTCAAGAGA GTTCAGAGGCAGG ATTCACTTTTTTG TAC-3' and reverse, 5'-AAAAAAGTGAATCCTGCCTCTGAACTCTCT TGAAGTTCAG AGGCAGGATTCACGGG-3'; GR127 (targeting RAGE mRNA 438-456) forward, 5'-GATCCCCGCCTCTGAACTCACAGCCATTCAAGAGAT GGCTGTGAGTTCA GAGGCTTTTTTGTAC-3' and reverse, 5'-AAAAAAGCCTCTGAACTCACAGCCATCTCTTGAAT GGCTGTGAGTTCAGAGGCGGG-3'; GR128 (targeting RAGE mRNA 780-798) forward, 5'-GATCCCCGAAGG TGGAACAGTCGCTCTT CAAGAGAGAGCGACTGTTCC ACCTTCTTTTTTGTAC-3' and reverse, 5'-AAAAAAGAA GGTGGAACAGTCGCTCTCTCTTGAAGAGCGACTGTTC CACCTTCGGG-3'; GR129 (targeting RAGE mRNA 1136-1154) forward, 5'-GATCCCCGCGAAAACGACAACCC AGATTCAAGAGATCTGGGTTGTCGT TTTCGCTTTTTT
GTAC-3' and reverse, 5'-AAAAAAGCGAAAACGACAACCC AGATCTCTT GAATCTGGGTTGTCGTTTTCGCGGG-3'.

The $B g l \mathrm{II}$ and $K p n \mathrm{I}$ restriction sites and the hairpin structure sequences were also added to the two ends of another pair of non-specific siRNA oligonucleotide sequences (not homologous to rat RAGE mRNA; confirmed using BLAST). It was named NS. NS forward, 5'-GATCCCCTTCTCCGAACGTGTCACG TTT CAAGAGAACGTGACACGTTCGGAGAATTTTTTGA TC-3' and reverse, 5'-AAAAAATTCTCCGAA CGTGTCACG TTCTCTTGAAACGTGACACGTTCGGAGAAGGG-3'.

Construction of specific siRNA expression vectors. The vector pAKD.CMV.bGlobin.eGFP.H1.shRNA was first linearized by restriction enzyme digestion at the $B g l \mathrm{II}$ and $K p n I$ sites and then re-connected using the annealed double-stranded DNA fragments GR125, GR126, GR127, GR128 or GR129. Thus, the RAGE-specific siRNA expression vectors pAKD-GR125, pAKD-GR126, pAKD-GR127, pAKD-GR128 and pAKD-GR129 were constructed. The non-specific siRNA expression vector $\mathrm{pAKD}-\mathrm{NS}$, which also expressed green fluorescent protein (GFP), was constructed and used as the control.

Cell transfection. RAGE siRNA expression vectors (pAKD-GR125,pAKD-GR126,pAKD-GR127,pAKD-GR128 and pAKD-GR129) were transfected into primary rat HSCs separately at multiplicities of infections (MOIs) of 20, 100, 200 and 1,000. Untreated and unspecific siRNA-transfected primary rat HSCs served as the controls. The medium was replaced with serum-free Dulbecco's modified Eagle's medium prior to transfection. Total RNA was extracted and the RAGE mRNA levels were determined using quantitative polymerase chain reaction (qPCR) following incubation for $48 \mathrm{~h}$.

The specific siRNA expression vectors that resulted in maximum inhibition of RAGE gene expression were selected and transfected into primary rat HSCs and cultured for five days. Untreated and unspecific siRNA-transfected primary rat HSCs were used as the controls. The cells were harvested following incubation for 24,48 or $72 \mathrm{~h}$, respectively, and the total RNA was extracted. The efficiency of RAGE gene silencing was assessed using qPCR.

Animal model and protocol. Six-week-old male Sprague-Dawley (SD) rats weighing 200 $\pm 30 \mathrm{~g}$ were purchased from the Shanghai Laboratory Animal Center of the Chinese Academy of Sciences (Shanghai, China). They were housed in the Animal Experiment Center of Medical College, Southeast University (Nanjing, China) under a 12-h dark/light cycle, and water and a standard diet were available ad libitum. The SD rats $(n=108)$ were divided randomly into two groups: A normal control group (NC; $n=18)$ and a model group $(n=90)$. The rats in the NC group were injected intraperitoneally with refined olive oil $(2 \mathrm{ml} / \mathrm{kg})$ twice weekly for six weeks and the rats in the model group were injected intraperitoneally with $50 \%$ $\mathrm{CCl}_{4}\left(2 \mathrm{ml} / \mathrm{kg} ; \mathrm{CCl}_{4} /\right.$ olive oil=1:1) twice weekly for six weeks to generate the hepatic fibrosis model. The successfully established model rats were then divided randomly into five groups, including the fibrosis model group (FM; $n=18)$, the low-dose therapeutic group (LT; $n=18$ ), the medium-dose therapeutic group (MT; n=18), the high-dose therapeutic group (HT; $=18)$ and the non-specific siRNA control group (NS; $n=18)$. The 
rats in the NC group and the FM group were injected with physiological saline $(2 \mathrm{ml} / \mathrm{kg})$ via the tail vein twice weekly for six weeks. The rats in the LT, MT and HT groups were injected with specific recombinant RAGE-targeted siRNA expression vectors at doses of $4 \times 10^{8}, 2 \times 10^{9}$ or $1 \times 10^{10}$ particles via tail vein injections twice weekly for six weeks. The rats in the NS group were injected with recombinant non-specific siRNA expression vectors at a dose of $1 \times 10^{10}$ via tail vein injections twice weekly for six weeks. In total, six rats from the NC group and each of the other groups were sacrificed two, four or six weeks after injection. All rats were sacrificed three days after their final injection. Following sacrification, blood was obtained from the cardiac cavity and the liver was removed, weighed and processed.

The study protocol was approved by the Animal Research Ethics Committee of Medical College, Southeast University (Nanjing, China).

Biochemical analysis of serum. Serum was collected from the blood samples by centrifuging at $10,000 \mathrm{x}$ g for $8 \mathrm{~min}$ at $4^{\circ} \mathrm{C}$. The serum levels of alanine aminotransferase (ALT), aspartate aminotransferase (AST), alkaline phosphatase (ALP) and total bilirubin (TBIL) were measured using a Beckman LX20 autoanalyzer. The serum levels of tumor necrosis factor- $\alpha$ (TNF- $\alpha$ ), interleukin-6 (IL-6), hyaluronic acid (HA), procollagen type III (PCIII) and laminin ( $\mathrm{LN}$ ) were determined using radioimmunoassays, according to the methods of Barouch et al (16).

Histological examination. Serial sections of liver tissue were prepared for pathological examination by staining with hematoxylin and eosin (H\&E) and Masson. Two pathologists examined the slides independently under a light microscope. The severity of inflammation activity and fibrosis were graded based on the Knodell HAI evaluation system and Ishak-modified system $(17,18)$. Inflammatory activity grading and fibrosis staging were recorded using five random fields, and the mean value was used for analysis.

Total RNA extraction and $q P C R$ assay. Total RNA was extracted from rat liver samples using TRIzol reagent (Invitrogen, St. Louis, MO, USA) according to the manufacturer's instructions. The RNA purity and concentration were determined and RNA was then reverse transcribed. qPCR was performed using a LightCycler PCR instrument with SYBR ${ }^{\circledR}$ green as the detection fluorophore (Applied Biosystems, Foster City, CA, USA). The thermal profile for PCR consisted of activation at $95^{\circ} \mathrm{C}$ for $3 \mathrm{~min}$, followed by 40 cycles of PCR at $95^{\circ} \mathrm{C}$ for $20 \mathrm{sec}, 60^{\circ} \mathrm{C}$ for $30 \mathrm{sec}$, and $72^{\circ} \mathrm{C}$ for $60 \mathrm{sec}$. Hepatic mRNA expression of type I collagen (collagen I), RAGE, $\alpha$-smooth muscle actin ( $\alpha$-SMA) and NF- $\kappa B$ were evaluated using qPCR with $\beta$-actin used as the endogenous control. The $\Delta \Delta C T$ method was used to calculate relative differences in the expression levels of each target gene.

Recombinant virus expression by fluorescence microscopy analysis. Sections of rapidly frozen liver tissue were generated using a freezing microtome and were observed under a fluorescence microscope. The amount of recombinant virus expression was assessed based on GFP expression.

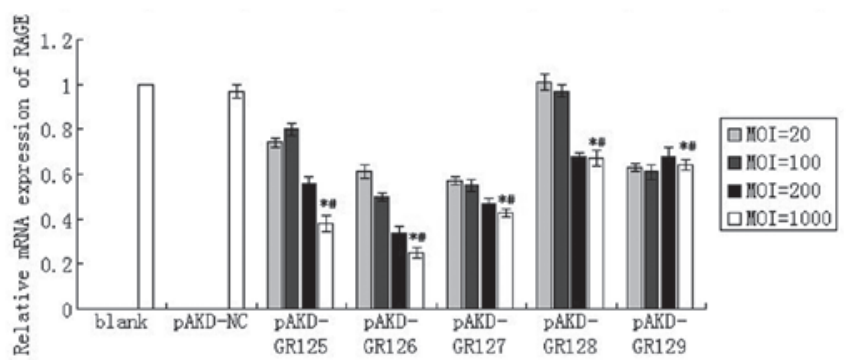

Figure 1. Effect of different doses of RAGE-specific siRNA on the expression of RAGE mRNA in primary rat hepatic stellate cells. The expression of RAGE mRNA relative to $\beta$-actin mRNA was quantified using quantitative polymerase chain reaction. The changes were expressed as the percentage of the respective blank. ${ }^{*} \mathrm{P}<0.01$ vs. blank and ${ }^{\#} \mathrm{P}<0.01$ vs. pAKD-NS. RAGE, receptor for advanced glycation end products; siRNA, small interfering RNA; MOI, multiplicity of infections; NC, normal control.

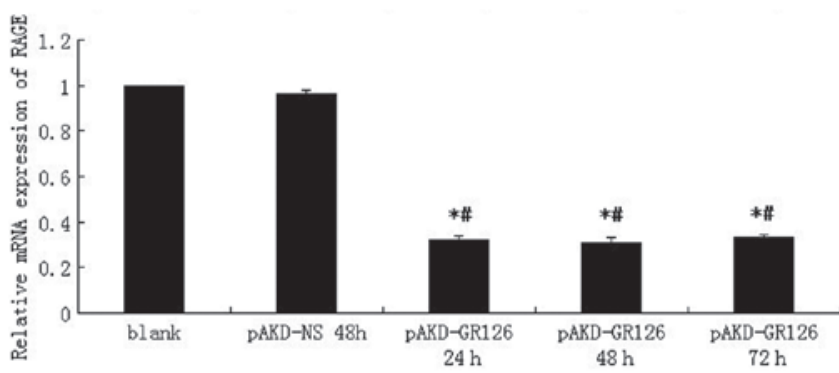

Figure 2. Effect of RAGE-specific siRNA on the expression of RAGE mRNA in primary rat HSCs at various time-points. The expression of RAGE mRNA relative to $\beta$-actin mRNA was quantified using quantitative polymerase chain reaction and the changes were expressed as the percentage of the respective blank. $\mathrm{P}<0.01$ vs. blank and ${ }^{\#} \mathrm{P}<0.01$ vs. pAKD-NS $48 \mathrm{~h}$. RAGE, receptor for advanced glycation end products; HSCs, hepatic stellate cells; siRNA, small interfering RNA.

Statistical analysis. Data are expressed as the mean \pm standard deviation. Statistical analyses were performed with the SPSS statistical software package (version 17.0; SPSS, Inc., Chicago, IL, USA) using a one-way analysis of variance or independent-samples t-tests, as appropriate. $\mathrm{P}<0.05$ was considered to indicate a statistically significant difference.

\section{Results}

Effect of specific RAGE-targeted siRNA on RAGE expression in primary rat HSCs. As compared with the untreated primary rat HSCs (blank) and the cells treated with pAKD-NS, the expression of RAGE mRNA was significantly downregulated in primary rat HSCs treated with pAKD-GR125 $(\mathrm{P}<0.05)$, pAKD-GR126 $(\mathrm{P}<0.05), \mathrm{pAKD}-\mathrm{GR} 127(\mathrm{P}<0.05)$, pAKD-GR128 $(\mathrm{P}<0.05)$ and pAKD-GR129 $(\mathrm{P}<0.05)$. The levels of RAGE mRNA decreased in a dose-dependent manner over MOIs of 20-1,000. In particular, the largest decrease was observed following treatment with pAKD-GR126 at an MOI of 1,000 (Fig. 1). The expression of RAGE mRNA was downregulated in primary rat HSCs treated with pAKD-GR126 at $24 \mathrm{~h}(\mathrm{P}<0.05), 48 \mathrm{~h}(\mathrm{P}<0.05)$ and $72 \mathrm{~h}(\mathrm{P}<0.05)$ compared with the blank cells. However, the inhibition of RAGE mRNA expression was not different between the treatment groups ( $\mathrm{P}>0.05$; Fig. 2). These results 


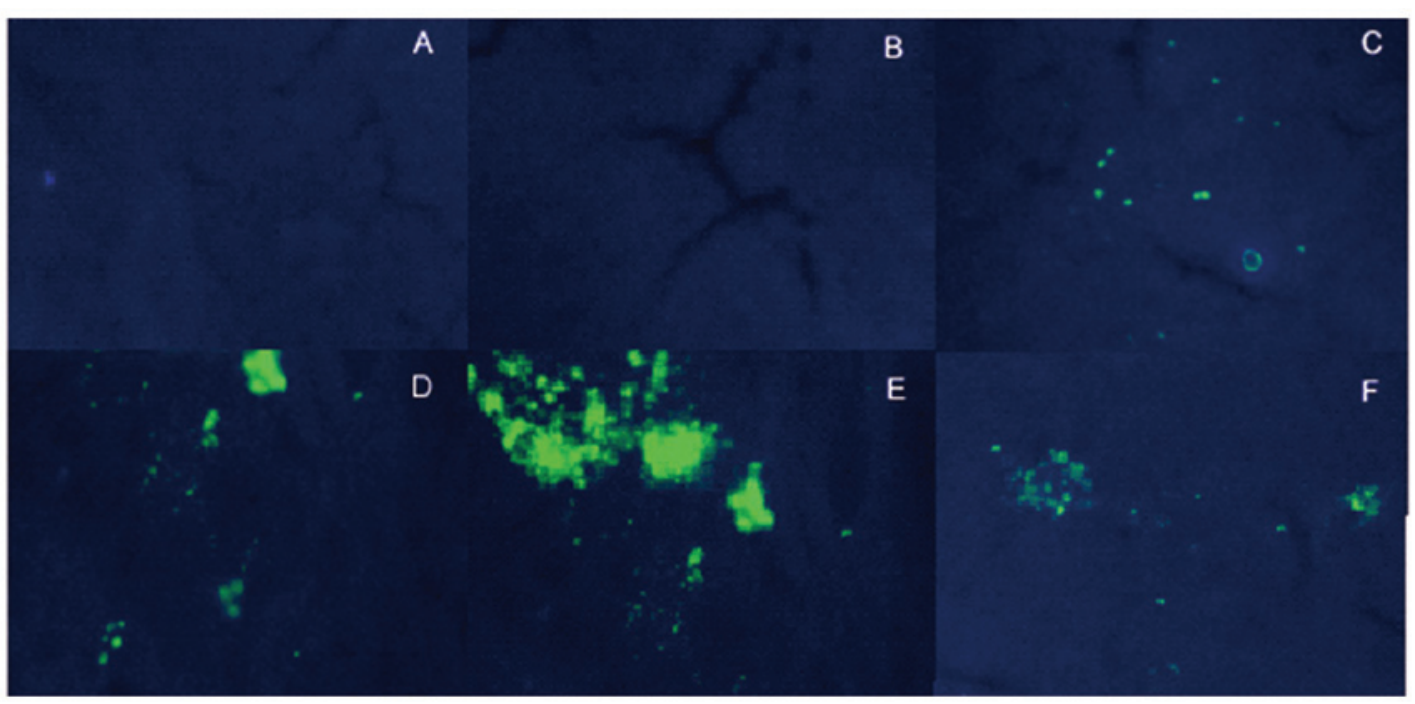

Figure 3. Expression of GFP in liver tissues. GFP fluorescence of liver tissues in the different groups was detected using a fluorescence microscope. (A) Fluorescence image of the liver tissue in the NC group; (B) fluorescence image of the liver tissue in the FM group; (C) fluorescence image of the liver tissue in the LT group; (D) fluorescence image of the liver tissue in the MT group; (E) fluorescence image of the liver tissue in the HT group, (F) fluorescence image of the liver tissue in the NS group. A-F, magnification, x100. NC, normal control; FM, fibrosis model; LT, low-dose therapeutic; MT, medium-dose therapeutic; HT, high-dose therapeutic; NS, non-specific siRNA control; GFP, green fluorescent protein.

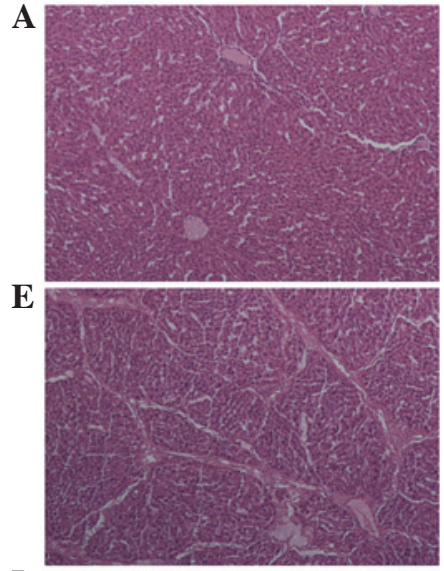

I

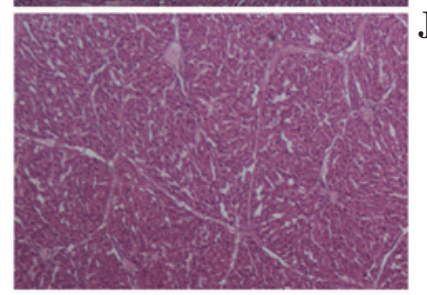

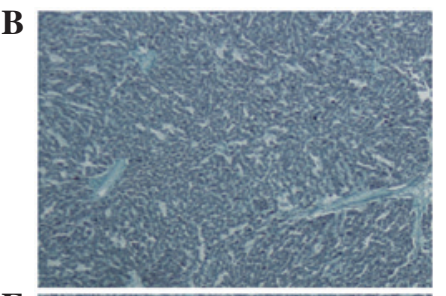

F

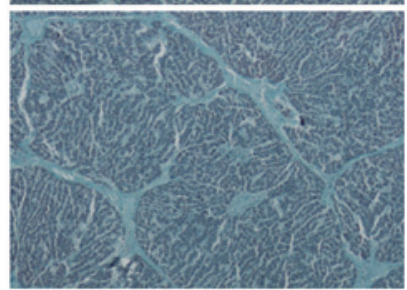

$\mathbf{J}$

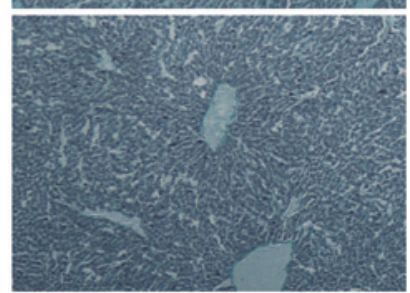

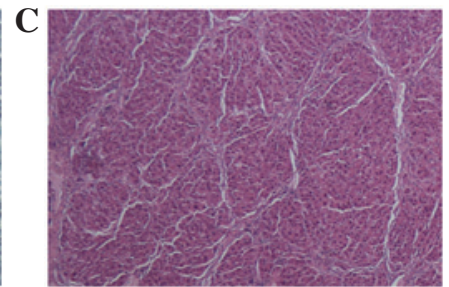

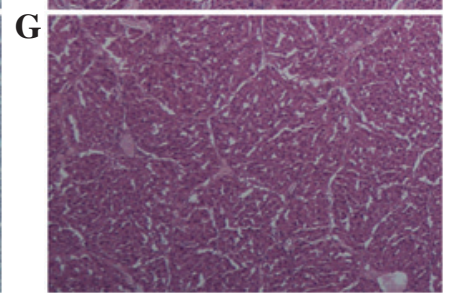

$\mathbf{K}$

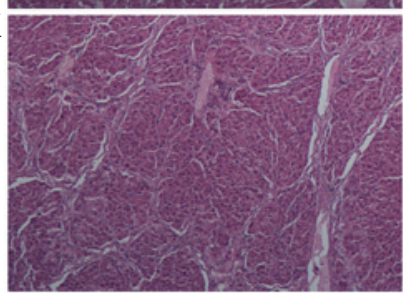

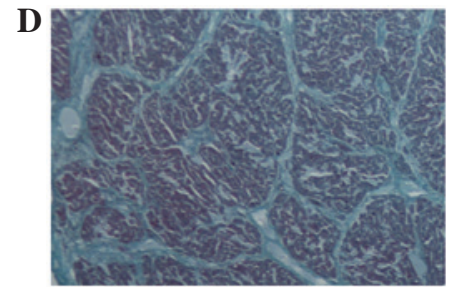

$\mathbf{H}$

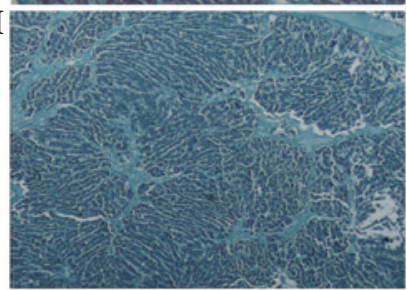

$\mathbf{L}$

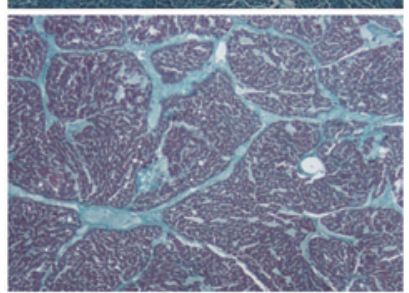

Figure 4. Histological examination of the effect of specific RAGE-targeted siRNA on rat hepatic fibrosis based on H\&E and Masson staining. (A and B) NC; (C and D) FM; (E and F) LT; (G and H) MT; (I and J) HT; (K and L) NS. (A, C, E, G, I and K) H\&E staining (magnification, x40); (B, D, F, H, J and L) Masson staining (magnification, x100). RAGE, receptor for advanced glycation end products; NC, normal control; FM, fibrosis model; LT, low-dose therapeutic; MT, medium-dose therapeutic; HT, high-dose therapeutic; NS, non-specific siRNA control; H\&E, hematoxylin and eosin; siRNA, small interfering RNA.

indicated that the RAGE-specific siRNA expressed by the pAKD-GR126 vector effectively inhibited RAGE gene expression. Therefore, pAKD-GR126 was selected for use in the subsequent animal experiment.

Observation of GFP expression in transfected cells. The GFP gene expressed by the pAKD-GR126 vector was used to trace siRNA expression. Whether the vector was transfected into liver tissues was judged from the expression of the GFP. Following sacrification, sections of rapidly frozen liver tissue were generated using a freezing microtome and were observed under a fluorescence microscope. Bright GFP fluorescence was observed in the liver tissues of therapeutic groups (LT, MT and HT group) and the NS group; however, not in the FM or NC groups (Fig. 3). These results demonstrated that pAKD-GR126 was successfully transfected into the rat model and expressed in liver tissues.

Effect of RAGE suppression on histological changes in rat liver. A histological analysis of the rat liver sections was 
conducted, which were collected three days after the final injections, based on $\mathrm{H} \& \mathrm{E}$ and Masson staining. In the FM and NS groups, robust piecemeal or bridging necrosis, inflammatory-cell infiltration and connective tissue hyperplasia were observed in the portal area, and pseudo-lobular formation was also observed, whereas no hepatocellular necrosis, inflammatory cell infiltration or fibroplasia was observed in the NC group. Compared with the FM and NS groups, the severity of hepatic inflammation and fibroplasia was significantly decreased in the therapeutic groups (Fig. 4). Using Knodell HAI and Ishak-modified systems, the inflammatory activity was graded and the fibrosis of rat livers was staged in each group. The inflammatory activity and fibrosis scores were significantly different among the six groups $\left(\chi^{2}=24.915, \mathrm{P}<0.01\right.$ and $\chi^{2}=27.580, P<0.01$, respectively; Table I), and the scores of each therapeutic group were significantly different compared with the FM group and the NS group $(\mathrm{P}<0.01)$. These results suggested that RAGE may be important in inflammatory activity and the formation of fibrosis in rat liver.

Effect of RAGE suppression on the liver function of rats. The serum levels of ALT, AST, ALP and TBIL reflect liver function and hepatocyte injury in the liver. Compared with the therapeutic groups and the NC group, the levels of serum ALT, AST, ALP and TBIL in the FM group and the NS group were significantly higher $(\mathrm{P}<0.01$; Table II). When compared with the FM group, following six weeks of RAGE suppression therapy, the serum levels of ALT in the LT, MT and HT groups were reduced by $65.04(\mathrm{P}<0.01), 72.42(\mathrm{P}<0.01)$ and 81.24\% ( $\mathrm{P}<0.01)$, respectively. AST was reduced by 55.22 $(\mathrm{P}<0.01), 63.60(\mathrm{P}<0.01)$ and $71.46 \%(\mathrm{P}<0.01)$. ALP decreased by $39.79(\mathrm{P}<0.01), 52.07(\mathrm{P}<0.01)$ and $60.51 \%(\mathrm{P}<0.01)$ and TBIL decreased by $39.61(\mathrm{P}<0.01), 60.39(\mathrm{P}<0.01)$ and $74.12 \%$ $(\mathrm{P}<0.01)$, respectively. These results demonstrated that the suppression of RAGE inhibits the increase in ALT, AST, ALP and TBIL. In addition, every therapeutic group also demonstrated statistically significant differences $(\mathrm{P}<0.01)$ in all four biochemical markers following 2, 4 or 6 weeks of injections, indicating that the effect of RAGE gene silencing therapy on serum ALT, AST, ALP and TBIL may depend on time to a certain degree.

RAGE-specific siRNA significantly reduces fibrosis-marker levels in rat serum. HA, LN and PCIII are the main components of ECM and their serum levels may indirectly reflect the progression of hepatic fibrogenesis. The levels of serum HA, LN and PCIII were significantly lower in the therapeutic groups and the NC group $(\mathrm{P}<0.01$; Table III) than in the FM and NS groups. As compared with the FM group, following six weeks of RAGE-suppression therapy, the levels of HA in the LT, MT and HT groups were reduced by $26.30(\mathrm{P}<0.01)$, $38.71(\mathrm{P}<0.01)$ and $50.16 \%(\mathrm{P}<0.01)$, respectively. $\mathrm{LN}$ was reduced by $9.34(\mathrm{P}<0.01), 16.91(\mathrm{P}<0.01)$ and $31.08 \%(\mathrm{P}<0.01)$, and PCIII decreased by $26.62(\mathrm{P}<0.01), 41.20(\mathrm{P}<0.01)$ and $50.26 \%(\mathrm{P}<0.01)$, respectively. These results demonstrated that the suppression of RAGE significantly decreased the levels of serum PCIII, HA and LN in rats.

Effect of specific RAGE-targeting siRNA on RAGE expression in rat liver tissues. RAGE mRNA expression in rat liver

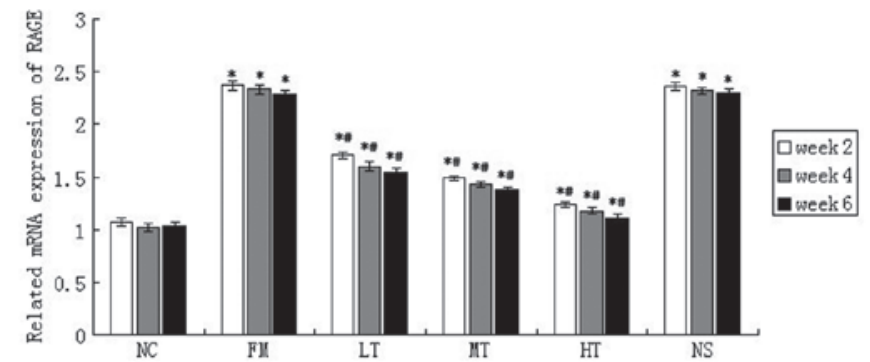

Figure 5. Relative mRNA expression of RAGE in rat liver tissues of the different groups. ${ }^{*} \mathrm{P}<0.01$ vs. NC; ${ }^{\text {}} \mathrm{P}<0.01$ vs. FM. RAGE, receptor for advanced glycation end products; FM, fibrosis model; NC, normal control; FM, fibrosis model; LT, low-dose therapeutic; MT, medium-dose therapeutic; HT, high-dose therapeutic; NS, non-specific siRNA control.

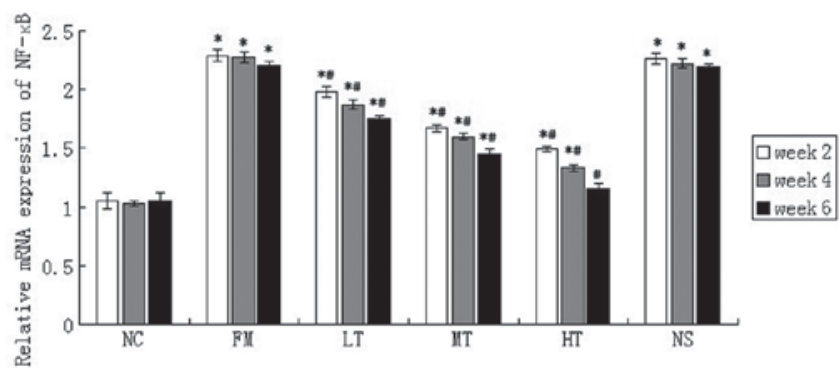

Figure 6. Relative mRNA expression of NF- $\mathrm{BB}$ in rat liver tissues of the different groups. ${ }^{*} \mathrm{P}<0.01$ vs. NC; ${ }^{"} \mathrm{P}<0.01$ vs. FM. FM, fibrosis model; NF-кB, nuclear factor-кB; NC, normal control; FM, fibrosis model; LT, low-dose therapeutic; MT, medium-dose therapeutic; HT, high-dose therapeutic; NS, non-specific siRNA control.

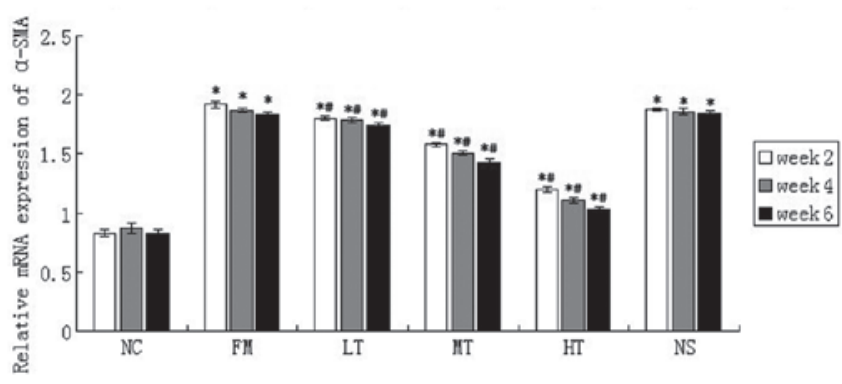

Figure 7. Relative mRNA expression of $\alpha$-SMA in rat liver tissues of the different groups. ${ }^{~} \mathrm{P}<0.01$ vs. $\mathrm{NC} ;{ }^{~} \mathrm{P}<0.01$ vs. FM. FM, fibrosis model; $\alpha$-SMA, $\alpha$-smooth muscle actin; NC, normal control; FM, fibrosis model; LT, low-dose therapeutic; MT, medium-dose therapeutic; HT, high-dose therapeutic; NS, non-specific siRNA control.

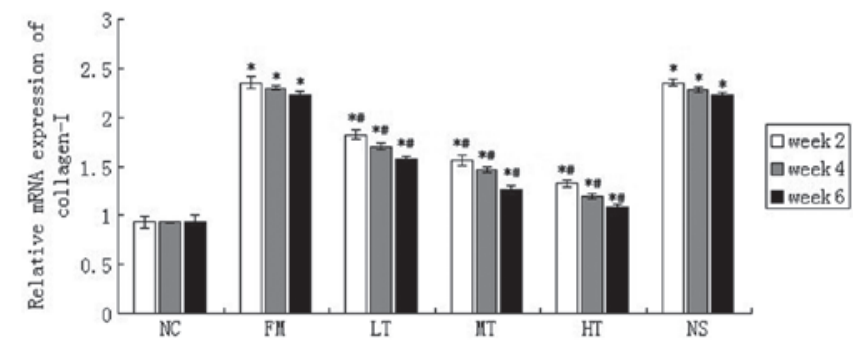

Figure 8. Relative mRNA expression of collagen I in rat liver tissues of the different groups. ${ }^{\text {P }}<0.01$ vs. NC; ${ }^{\sharp} \mathrm{P}<0.01$ vs. FM. FM, fibrosis model; $\mathrm{NC}$, normal control; FM, fibrosis model; LT, low-dose therapeutic; MT, medium-dose therapeutic; HT, high-dose therapeutic; NS, non-specific siRNA control. 
Table I. Effects of specific RAGE-targeted siRNA on rat liver tissue inflammation and fibrosis.

\begin{tabular}{|c|c|c|c|c|c|c|c|c|c|c|c|c|c|}
\hline \multirow[b]{2}{*}{ Group } & \multirow[b]{2}{*}{$\mathrm{n}$} & \multicolumn{5}{|c|}{ Inflammation grade } & \multirow{2}{*}{$\begin{array}{c}\text { Average } \\
\text { rank }\end{array}$} & \multicolumn{5}{|c|}{ Fibrosis stage } & \multirow{2}{*}{$\begin{array}{c}\text { Average } \\
\text { rank }\end{array}$} \\
\hline & & 0 & I & II & III & IV & & 0 & I & II & III & IV & \\
\hline $\mathrm{NC}$ & 6 & 3 & 0 & 0 & 0 & 0 & 2.50 & 3 & 0 & 0 & 0 & 0 & 2.00 \\
\hline FM & 6 & 0 & 0 & 0 & 2 & 4 & $28.00^{\mathrm{a}}$ & 0 & 0 & 0 & 1 & 5 & $26.75^{\mathrm{a}}$ \\
\hline LT & 6 & 0 & 2 & 3 & 1 & 0 & $15.33^{\mathrm{a}, \mathrm{b}}$ & 0 & 1 & 3 & 2 & 0 & $15.58^{\mathrm{a}, \mathrm{b}}$ \\
\hline MT & 6 & 0 & 3 & 3 & 0 & 0 & $12.75^{\mathrm{a}, \mathrm{b}}$ & 0 & 3 & 2 & 1 & 0 & $12.17^{\mathrm{a}, \mathrm{b}}$ \\
\hline HT & 6 & 1 & 3 & 2 & 0 & 0 & $10.33^{\mathrm{a}, \mathrm{b}}$ & 0 & 4 & 2 & 0 & 0 & $10.00^{\mathrm{a}, \mathrm{b}}$ \\
\hline NS & 6 & 0 & 0 & 1 & 2 & 3 & $25.83^{\mathrm{a}}$ & 0 & 0 & 0 & 0 & 6 & $28.00^{\mathrm{a}}$ \\
\hline
\end{tabular}

The rank sum test of the grade of inflammation in six groups, $\chi^{2}=24.915, \mathrm{P}<0.01$. The rank sum test of the fibrosis stage in six groups, $\chi^{2}=27.580$, $\mathrm{P}<0.01$. ${ }^{\mathrm{P}} \mathrm{P}<0.01$ vs. NC; ${ }^{\mathrm{P}} \mathrm{P}<0.01$ vs. FM. RAGE, receptor for advanced glycation end products; NC, normal control; FM, fibrosis model; LT, low-dose therapeutic; MT, medium-dose therapeutic; HT, high-dose therapeutic; NS, non-specific siRNA control; siRNA, small interfering RNA.

Table II. Effect of specific RAGE-targeted siRNA on ALT, AST, ALP and TBIL levels in rats.

\begin{tabular}{|c|c|c|c|c|c|c|c|}
\hline & Time & $\mathrm{NC}$ & FM & LT & MT & HT & NS \\
\hline \multirow[t]{3}{*}{$\operatorname{ALT}(\mathrm{U} / \mathrm{l})$} & Week 2 & $41.0 \pm 2.0$ & $308.8 \pm 17.1^{\mathrm{a}}$ & $146.5 \pm 9.8^{\mathrm{a}, \mathrm{b}}$ & $121.2 \pm 8.4^{\mathrm{a}, \mathrm{b}}$ & $92.0 \pm 7.2^{\mathrm{a}, \mathrm{b}}$ & $305.0 \pm 13.1^{\mathrm{a}}$ \\
\hline & Week 4 & $41.0 \pm 3.6$ & $286.7 \pm 11.3^{\mathrm{a}}$ & $108.0 \pm 8.3^{\mathrm{a}, \mathrm{b}}$ & $91.3 \pm 7.6^{\mathrm{a}, \mathrm{b}}$ & $68.3 \pm 6.7^{\mathrm{a}, \mathrm{b}}$ & $288.5 \pm 9.7^{\mathrm{a}}$ \\
\hline & Week 6 & $42.7 \pm 2.5$ & $270.8 \pm 13.2^{\mathrm{a}}$ & $94.7 \pm 9.5^{\mathrm{a}, \mathrm{b}}$ & $74.7 \pm 6.7^{\mathrm{a}, \mathrm{b}}$ & $50.8 \pm 5.5^{\mathrm{a}, \mathrm{b}}$ & $279.3 \pm 8.5^{\mathrm{a}}$ \\
\hline \multirow[t]{3}{*}{$\operatorname{AST}(\mathrm{U} / \mathrm{l})$} & Week 2 & $96.7 \pm 4.7$ & $396.2 \pm 10.2^{\mathrm{a}}$ & $197.2 \pm 6.8^{\mathrm{a}, \mathrm{b}}$ & $181.3 \pm 8.8^{\mathrm{a}, \mathrm{b}}$ & $176.0 \pm 6.1^{\mathrm{a}, \mathrm{b}}$ & $405.3 \pm 9.4^{\mathrm{a}}$ \\
\hline & Week 4 & $93.0 \pm 5.6$ & $380.5 \pm 4.5^{\mathrm{a}}$ & $182.8 \pm 6.5^{\mathrm{a}, \mathrm{b}}$ & $153.2 \pm 5.9^{\mathrm{a}, \mathrm{b}}$ & $130.5 \pm 6.4^{a, b}$ & $377.7 \pm 5.9^{\mathrm{a}}$ \\
\hline & Week 6 & $95.7 \pm 9.1$ & $366.2 \pm 9.0^{\mathrm{a}}$ & $164.0 \pm 9.4^{\mathrm{a}, \mathrm{b}}$ & $133.3 \pm 6.6^{\mathrm{a}, \mathrm{b}}$ & $104.5 \pm 6.7^{\mathrm{a}, \mathrm{b}}$ & $371.2 \pm 7.6^{\mathrm{a}}$ \\
\hline \multirow[t]{3}{*}{$\operatorname{ALP}(\mathrm{U} / \mathrm{l})$} & Week 2 & $88.0 \pm 4.6$ & $291.0 \pm 7.8^{\mathrm{a}}$ & $223.3 \pm 4.8^{\mathrm{a}, \mathrm{b}}$ & $205.8 \pm 6.2^{\mathrm{a}, \mathrm{b}}$ & $189.8 \pm 8.2^{\mathrm{a}, \mathrm{b}}$ & $291.8 \pm 6.4^{\mathrm{a}}$ \\
\hline & Week 4 & $82.7 \pm 4.0$ & $278.3 \pm 9.1^{\mathrm{a}}$ & $186.2 \pm 4.7^{\mathrm{a}, \mathrm{b}}$ & $149.5 \pm 5.2^{\mathrm{a}, \mathrm{b}}$ & $134.3 \pm 5.9^{\mathrm{a}, \mathrm{b}}$ & $283.5 \pm 4.9^{\mathrm{a}}$ \\
\hline & Week 6 & $86.7 \pm 4.2$ & $272.7 \pm 6.0^{\mathrm{a}}$ & $164.2 \pm 5.4^{\mathrm{a}, \mathrm{b}}$ & $130.7 \pm 7.4^{\mathrm{a}, \mathrm{b}}$ & $107.7 \pm 8.3^{\mathrm{a}, \mathrm{b}}$ & $271.0 \pm 7.3^{\mathrm{a}}$ \\
\hline \multirow[t]{3}{*}{ TBIL $(\mu \mathrm{mol} / \mathrm{l})$} & Week 2 & $4.1 \pm 0.2$ & $29.9 \pm 0.8^{\mathrm{a}}$ & $19.2 \pm 0.6^{\mathrm{a}, \mathrm{b}}$ & $16.8 \pm 0.7^{\mathrm{a}, \mathrm{b}}$ & $13.2 \pm 0.7^{\mathrm{a}, \mathrm{b}}$ & $29.5 \pm 0.6^{\mathrm{a}}$ \\
\hline & Week 4 & $4.2 \pm 0.1$ & $27.8 \pm 0.7^{\mathrm{a}}$ & $16.8 \pm 0.6^{\mathrm{a}, \mathrm{b}}$ & $12.8 \pm 0.6^{\mathrm{a}, \mathrm{b}}$ & $8.6 \pm 0.6^{\mathrm{a}, \mathrm{b}}$ & $27.9 \pm 0.8^{\mathrm{a}}$ \\
\hline & Week 6 & $4.1 \pm 0.2$ & $25.5 \pm 0.9^{\mathrm{a}}$ & $15.4 \pm 0.8^{\mathrm{a}, \mathrm{b}}$ & $10.1 \pm 0.7^{\mathrm{a}, \mathrm{b}}$ & $6.6 \pm 0.9^{\mathrm{a}, \mathrm{b}}$ & $24.3 \pm 0.6^{\mathrm{a}}$ \\
\hline
\end{tabular}

${ }^{\mathrm{a}} \mathrm{P}<0.01$ vs. NC; ${ }^{\mathrm{b}} \mathrm{P}<0.01$ vs. FM. RAGE, receptor for advanced glycation end products; NC, normal control; FM, fibrosis model; LT, low-dose therapeutic; MT, medium-dose therapeutic; HT, high-dose therapeutic; NS, non-specific siRNA control; ALT, alanine aminotransferase; AST, aspartate aminotransferase; ALP, alkaline phosphatase; TBIL, total bilirubin; siRNA, small interfering RNA.

Table III. Effect of RAGE-targeted siRNA on markers of fibrosis (HA, LN and PCIII) in rats.

\begin{tabular}{lccccccc}
\hline \multirow{2}{*}{ HA $(\mu \mathrm{g} / \mathrm{l})$} & Time & NC & FM & LT & MT & HT & NS \\
& Week 2 & $111.3 \pm 6.1$ & $431.7 \pm 6.3^{\mathrm{a}}$ & $325.7 \pm 5.2^{\mathrm{a}, \mathrm{b}}$ & $280.0 \pm 6.1^{\mathrm{a}, \mathrm{b}}$ & $244.7 \pm 6.3^{\mathrm{a}, \mathrm{b}}$ & $418.0 \pm 10.0^{\mathrm{a}}$ \\
& Week 4 & $115.3 \pm 4.2$ & $422.0 \pm 5.1^{\mathrm{a}}$ & $309.2 \pm 6.4^{\mathrm{a}, \mathrm{b}}$ & $263.3 \pm 5.9^{\mathrm{a}, \mathrm{b}}$ & $227.0 \pm 6.4^{\mathrm{a}, \mathrm{b}}$ & $411.7 \pm 7.3^{\mathrm{a}}$ \\
& Week 6 & $115.0 \pm 5.3$ & $410.7 \pm 3.6^{\mathrm{a}}$ & $302.7 \pm 4.8^{\mathrm{a}, \mathrm{b}}$ & $251.7 \pm 5.9^{\mathrm{a}, \mathrm{b}}$ & $204.7 \pm 5.6^{\mathrm{a}, \mathrm{b}}$ & $403.7 \pm 6.1^{\mathrm{a}}$ \\
LN $(\mu \mathrm{g} / \mathrm{l})$ & Week 2 & $84.7 \pm 5.7$ & $231.0 \pm 6.7^{\mathrm{a}}$ & $216.7 \pm 6.2^{\mathrm{a}, \mathrm{b}}$ & $206.5 \pm 4.1^{\mathrm{a}, \mathrm{b}}$ & $194.5 \pm 6.2^{\mathrm{a}, \mathrm{b}}$ & $230.5 \pm 8.4^{\mathrm{a}}$ \\
& Week 4 & $83.7 \pm 4.2$ & $227.2 \pm 5.8^{\mathrm{a}}$ & $208.0 \pm 5.3^{\mathrm{a}, \mathrm{b}}$ & $197.3 \pm 5.4^{\mathrm{a}, \mathrm{b}}$ & $168.7 \pm 6.2^{\mathrm{a}, \mathrm{b}}$ & $220.7 \pm 9.2^{\mathrm{a}}$ \\
& Week 6 & $85.7 \pm 2.5$ & $221.7 \pm 6.0^{\mathrm{a}}$ & $201.0 \pm 4.2^{\mathrm{a}, \mathrm{b}}$ & $184.2 \pm 4.9^{\mathrm{a}, \mathrm{b}}$ & $152.8 \pm 5.1^{\mathrm{a}, \mathrm{b}}$ & $218.3 \pm 5.7^{\mathrm{a}}$ \\
\multirow{3}{*}{ PCIII $(\mu \mathrm{g} / \mathrm{l})$} & Week 2 & $108.0 \pm 2.0$ & $366.0 \pm 7.4^{\mathrm{a}}$ & $310.5 \pm 5.4^{\mathrm{a}, \mathrm{b}}$ & $275.0 \pm 6.3^{\mathrm{a}, \mathrm{b}}$ & $239.2 \pm 4.4^{\mathrm{a}, \mathrm{b}}$ & $374.7 \pm 5.3^{\mathrm{a}}$ \\
& Week 4 & $105.0 \pm 5.6$ & $356.5 \pm 7.9^{\mathrm{a}}$ & $279.5 \pm 7.3^{\mathrm{a}, \mathrm{b}}$ & $232.5 \pm 6.7^{\mathrm{a}, \mathrm{b}}$ & $195.0 \pm 5.9^{\mathrm{a}, \mathrm{b}}$ & $366.0 \pm 4.2^{\mathrm{a}}$ \\
& Week 6 & $107.3 \pm 6.8$ & $351.2 \pm 4.2^{\mathrm{a}}$ & $257.7 \pm 7.4^{\mathrm{a}, \mathrm{b}}$ & $206.5 \pm 6.5^{\mathrm{a}, \mathrm{b}}$ & $174.7 \pm 6.1^{\mathrm{a}, \mathrm{b}}$ & $360.8 \pm 4.7^{\mathrm{a}}$ \\
\hline
\end{tabular}

${ }^{\mathrm{a} P}<0.01$ vs. NC; ${ }^{\mathrm{b}} \mathrm{P}<0.01$ vs. FM. RAGE, receptor for advanced glycation end products; NC, normal control; FM, fibrosis model; LT, low-dose therapeutic; MT, medium-dose therapeutic; HT, high-dose therapeutic; NS, non-specific siRNA control; HA, hyaluronic acid; LN, laminin; PCIII, procollagen type III; siRNA, small interfering RNA. 
A

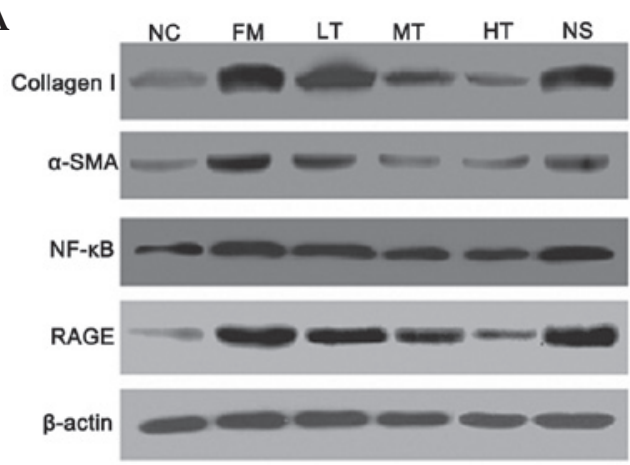

B

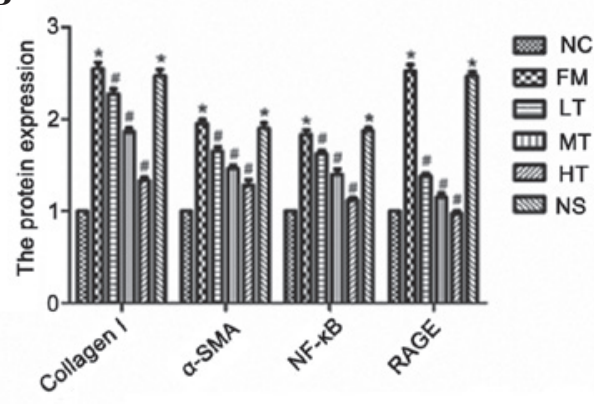

Figure 9. Effect of specific RAGE-targeted siRNA on the expression of 42-kD RAGE, 42-kD $\alpha$-SMA, 50-kD NF- $\kappa$ B and 120-kD collagen I in rats. (A) Protein expression of 42-kD RAGE, 42-kD $\alpha$-SMA, 50-kD NF- $\mathrm{BB}$ and 120-kD collagen I were determined using western blot analysis. (B) Amount of RAGE, $\alpha$-SMA, NF- $\kappa \mathrm{B}$ and collagen I was expressed relative to $\beta$-actin protein and was determined using densitometric scanning. The changes were expressed as the percentage of NC. ${ }^{*} \mathrm{P}<0.01$ vs. NC; ${ }^{\prime} \mathrm{P}<0.01$ vs. FM. RAGE, receptor for advanced glycation end products; $\alpha$-SMA, $\alpha$-smooth muscle actin; NF- $\kappa \mathrm{B}$, nuclear factor-кB; siRNA, small interfering RNA; NC, normal control; FM, fibrosis model; LT, low-dose therapeutic; MT, medium-dose therapeutic; HT, high-dose therapeutic; NS, non-specific siRNA control.

tissues was evaluated using qPCR. The mRNA expression of RAGE was low in normal rat liver tissues and it increased significantly following six weeks of $\mathrm{CCl}_{4}$ injections $(\mathrm{P}<0.01$; Fig. 5). Following RAGE gene-silencing therapy, the mRNA expression of RAGE in rats with hepatic fibrosis decreased. Following six weeks of therapy using a specific siRNA that targeted RAGE, the relative mRNA expression of RAGE in the LT, MT and HT groups decreased by $32.75(\mathrm{P}<0.01), 39.74$ $(\mathrm{P}<0.01)$ and $51.53 \%(\mathrm{P}<0.01)$, respectively, (Fig. 4) compared with the FM group. The mRNA expression of RAGE in the NS group was not significantly different from that in the FM group ( $\mathrm{P}>0.05)$. These results demonstrated that RAGE gene silencing effectively inhibited the expression of RAGE in rat livers.

Effect of the inhibition of RAGE, using specific siRNA, on the expression of $N F-\kappa B$. The mRNA expression of NF- $\kappa \mathrm{B}$ in rat liver tissues was evaluated using qPCR. NF- $\kappa \mathrm{B}$ mRNA expression was low in normal rat liver tissues and $\mathrm{CCl}_{4}$ injections caused a marked increase in the mRNA expression of NF- $\kappa \mathrm{B}$ $(\mathrm{P}<0.01$; Fig. 6). NF- $\kappa \mathrm{B}$ mRNA expression in rats with hepatic fibrosis decreased following RAGE gene-silencing therapy. Following six weeks of therapy using specific RAGE-targeted siRNA, the relative expression of NF- $\kappa \mathrm{B}$ mRNA in the LT, MT and HT groups decreased by $20.81(\mathrm{P}<0.01), 34.39(\mathrm{P}<0.01)$ and $47.96 \%(\mathrm{P}<0.01)$, respectively, (Fig. 5) compared with the FM group. No significant difference in NF- $\kappa$ B mRNA expression was identified between the FM and NS groups $(\mathrm{P}>0.05)$.

RAGE suppression-mediated inhibition of HSC activation. The expression of $\alpha$-SMA is an important marker that may indicate the activation of HSCs. The mRNA expression of $\alpha$-SMA in rat liver tissues was evaluated using $\mathrm{QPCR}$. As compared with the $\mathrm{NC}$ group, $\mathrm{CCl}_{4}$ induced a strong upregulation of $\alpha$-SMA mRNA, and RAGE-specific siRNA treatment significantly attenuated $\alpha$-SMA mRNA expression. Following six weeks of RAGE gene-silencing therapy, when compared with the FM group, the relative expression of $\alpha$-SMA mRNA in the LT, MT and HT group decreased by $4.92(\mathrm{P}<0.01), 21.86(\mathrm{P}<0.01)$ and $43.72 \%(\mathrm{P}<0.01)$, respectively, and no significant difference in the mRNA expression of $\alpha$-SMA was identified between the NS and FM groups ( $\mathrm{P}>0.05$; Fig. 7). These results suggested that RAGE suppression may inhibit HSC activation in vivo.

Effect of the suppression of RAGE using specific siRNAs on the mRNA expression of collagen I. The mRNA expression of collagen I in rat liver tissues was evaluated using qPCR. Collagen $\mathrm{I}$ is another important marker that indicates the activation of HSCs. Compared with the $\mathrm{NC}$ group, $\mathrm{CCl}_{4}$ injection markedly upregulated collagen I mRNA expression. Following RAGE-specific siRNA treatment for six weeks, the expression of collagen I mRNA significantly decreased in the LT group (28.83\%; $\mathrm{P}<0.01)$, the MT group $(43.24 \%$; $\mathrm{P}<0.01)$ and the HT group (51.35\%; $\mathrm{P}<0.01$; Fig. 8) as compared with the FM group. No significant difference in collagen I mRNA expression was observed between the NS and FM groups ( $\mathrm{P}>0.05$; Fig. 8). These results also demonstrated the possible effect of the inhibition of RAGE suppression on HSC activation in vivo.

Inhibition of the protein expression of RAGE, $N F-\kappa B, \alpha-S M A$ and collagen I by RAGE gene silencing. Following six weeks of RAGE gene-silencing therapy, rat livers were collected and the protein expression of RAGE, NF- $\kappa \mathrm{B}, \alpha-\mathrm{SMA}$ and collagen I was evaluated using western blot analysis. The protein expression of these four markers demonstrated a similar trend to that of their respective mRNA expression profiles. The protein expression of RAGE, NF- $\kappa \mathrm{B}, \alpha$-SMA and collagen I was significantly higher in the fibrosis model and was attenuated by RAGE gene-silencing therapy $(\mathrm{P}<0.01$; Fig. 9). These results indicated that these four molecules may be used as biomarkers of RAGE gene-silencing therapy, which attenuates rat hepatic fibrosis.

\section{Discussion}

The present study reported, for the first time, to the best of our knowledge, the mechanisms of therapeutic effects of specific RAGE-targeting siRNA on $\mathrm{CCl}_{4}$-induced hepatic fibrosis in rats. The RAGE-ligand axis has been demonstrated to be important in fibrogenesis and a previous study by our group demonstrated that RAGE gene silencing effectively prevented liver fibrosis in a rat model (15). However, the effect of siRNA targeted to RAGE on established hepatic fibrosis was yet to be elucidated. 
In the present study, SD rats were used to generate a model of $\mathrm{CCl}_{4}$-induced hepatic fibrosis. Following six weeks of $\mathrm{CCl}_{4}$ injections, the liver-function biomarkers (ALT, AST, ALP and TBIL), the grade of hepatitis and the stage of hepatic fibrosis were much higher in the rats in the FM group than in those in the $\mathrm{NC}$ group, and the majority of rats in the FM group had ascites. These results indicated that the rat hepatic fibrosis model was established following six weeks of intraperitoneal injections with $\mathrm{CCl}_{4}$. Following interference with the RAGE-specific siRNAs, the rats in the therapeutic groups demonstrated improved liver functions compared with those in the FM and NS groups $(\mathrm{P}<0.01$; Table II), and the hepatitis grade and the hepatic fibrosis stage were also lower. These data revealed the therapeutic effect of specific RAGEtargeted siRNA on $\mathrm{CCl}_{4}$-induced hepatic fibrosis in rats. These data demonstrated that RAGE mRNA and protein expression levels were low in the $\mathrm{NC}$ group and were increased in the FM group; however, following therapy with specific RAGEtargeted siRNA at varying doses, RAGE expression decreased to differing degrees ( $\mathrm{P}<0.01$; Figs. 5 and 9$)$. These data, together with the progression of hepatic fibrosis observed in the FM group, indicated that RAGE was involved in the development of hepatic fibrosis. Furthermore, based on the expression of $\mathrm{NF}-\kappa \mathrm{B}$ observed during hepatic fibrogenesis and its repression following therapy, RAGE may promote hepatic fibrosis via the $\mathrm{NF}-\kappa \mathrm{B}$ pathway. In the present study, the NF- $\kappa \mathrm{B}$ mRNA and protein levels were significantly higher in the FM group than in the $\mathrm{NC}$ or NS groups. In addition, $\mathrm{NF}-\kappa \mathrm{B}$ expression in the therapeutic groups was reduced compared with the FM and NS groups (Figs. 6 and 9) in parallel with RAGE expression. These data indicate that NF- $\kappa \mathrm{B}$ expression was inhibited by RAGE gene silencing. NF- $\kappa \mathrm{B}$ comprises a family of transcription factors that includes RelA (p65), NF- $\kappa$ B1 (p50 and p105), $\mathrm{NF}-\kappa \mathrm{B} 2$ (p52 and p100), c-Rel and RelB. These factors are key regulators of genes involved in inflammation, immunity, wound healing and acute-phase responses, proliferation and apoptosis $(19,20)$. NF- $\mathrm{B}$ is retained in an inactive form in the cytoplasm via its association with one of the $\mathrm{I} \kappa \mathrm{B}$ inhibitory proteins, including I $\kappa \mathrm{B}-\alpha$ (21). Following cellular stimulation, $\mathrm{I} \kappa \mathrm{B}-\alpha$ is phosphorylated and undergoes proteolysis in the proteasome complex, which enables NF- $\kappa \mathrm{B}$ to translocate into the nucleus where it regulates the expression of $>200$ genes that affect cell growth, survival and inflammation $(22,23)$. The binding of RAGE ligands to RAGE results in the generation of intracellular oxygen free radicals $(24,25)$. With persistent ligand binding, the elevated cellular oxidative stress finally leads to the activation of the redox-sensitive transcription factor $\mathrm{NF}-\kappa \mathrm{B}$ and subsequent $\mathrm{NF}-\kappa \mathrm{B}$-dependent gene expression $(11,14,24,25)$. Since the RAGE promoter is itself controlled by $\mathrm{NF}-\kappa \mathrm{B}(26)$, the sustained activation of $\mathrm{NF}-\kappa \mathrm{B}$ results in the upregulation of RAGE, which then further ensures maintenance and amplification of the signal, thereby enabling perpetual activation of $\mathrm{NF}-\kappa \mathrm{B}$.

In addition, there is a growing body of evidence demonstrating that NF- $\kappa \mathrm{B}$ may be important in HSC activation. The expression of $\alpha$-SMA and collagen I, which reflect HSC activation, was also lower in the therapeutic groups when compared with the FM and NS groups (Figs. 7-9). These data demonstrated that following RAGE gene-silencing-mediated reduction in the expression of $N F-\kappa B$ and its regulated cytokines, HSC activation may decrease. Quiescent HSCs demonstrate minimal levels of NF- $\kappa \mathrm{B}$ and contrast to activated HSCs that exhibit nuclear NF- $\mathrm{NB}$ associated with constitutive expression of $\mathrm{NF}-\kappa \mathrm{B}$-regulated genes, including intercellular adhesion molecule-1, monocyte chemoattractant protein-1, TNF- $\alpha$ and IL-6 $(27,28)$.

Furthermore, NF- $\mathrm{NB}$ is a cardinal regulator of the inflammatory response by controlling the expression of genes encoding cytokines. The accumulation of pro-inflammatory cytokines provokes quiescent HSCs to undergo significant morphological and functional changes, together termed 'activation', and they transdifferentiate into proliferative, fibrogenic and contractile myofibroblast-like cells, which are considered to be the primary ECM-producing cells during pathogenic fibrosis (29-31). In the present study, the serum levels of TNF- $\alpha$ and IL- 6 demonstrated similar trends to NF- $\mathrm{NB}$ as they are regulated by $\mathrm{NF}-\kappa \mathrm{B}$. Consequently, ECM synthesis also decreased and the degradation of ECM increased, resulting in reduced ECM deposition, which was evidenced by the reduced levels of HA, LN and PCIII (Table III). The inhibition of HSC activation and degradation of ECM may attenuate and even reverse the progression of hepatic fibrosis.

In conclusion, the present study demonstrated that specific RAGE-targeted siRNA inhibited RAGE gene expression effectively in a $\mathrm{CCl}_{4}$-induced rat model of hepatic fibrosis and attenuated the progression of established hepatic fibrosis. Furthermore, the antifibrotic effect of RAGE gene silencing may be mediated by the inhibition of $N F-\kappa B$ expression, which mediates the inflammatory response and the activation of HSCs. These findings, together with a previous study by our group (15), suggested that RAGE may be a new target for combating liver fibrosis and that RAGE-specific siRNA may be an effective candidate for preventing liver fibrogenesis.

\section{Acknowledgements}

This study was funded by the Natural Science Foundation of Jiangsu Province, China (no. BK2009284).

\section{References}

1. Anthony PP, Ishak KG, Nayak NC, Poulsen HE, Scheuer PJ and Sobin LH: The morphology of cirrhosis. Recommendations on definition, nomenclature, and classification by a working group sponsored by the World Health Organization. J Clin Pathol 31: 395-414, 1978.

2. Friedman SL, Roll FJ, Boyles J and Bissell DM: Hepatic lipocytes: the principal collagen-producing cells of normal rat liver. Proc Natl Acad Sci USA 82: 8681-8685, 1985.

3. Rippe RA: Life or death: the fate of the hepatic stellate cell following hepatic injury. Hepatology 27: 1447-1448, 1998.

4. Brandão DF, Ramalho LN, Ramalho FS, Zucoloto S, Martinelli Ade L and Silva Ode C: Liver cirrhosis and hepatic stellate cells. Acta Cir Bras 21 (Suppl 1): 54-57, 2006.

5. Lee UE and Friedman SL: Mechanisms of hepatic fibrogenesis. Best Pract Res Clin Gastroenterol 25: 195-206, 2011.

6. Neeper M, Schmidt AM, Brett J, et al: Cloning and expression of a cell surface receptor for advanced glycosylation end products of proteins. J Biol Chem 267: 14998-15004, 1992.

7. Sparvero LJ, Asafu-Adjei D, Kang R, et al: RAGE (Receptor for Advanced Glycation Endproducts), RAGE ligands, and their role in cancer and inflammation. J Transl Med 7: 17, 2009.

8. Schmidt AM, Yan SD, Yan SF and Stern DM: The biology of the receptor for advanced glycation end products and its ligands. Biochim Biophys Acta 1498: 99-111, 2000. 
9. Wautier MP, Chappey O, Corda S, Stern DM, Schmidt AM and Wautier JL: Activation of NADPH oxidase by AGE links oxidant stress to altered gene expression via RAGE. Am J Physiol Endocrinol Metab 280: E685-E694, 2001.

10. Mohamed AK, Bierhaus A, Schiekofer S, Tritschler H, Ziegler R and Nawroth PP: The role of oxidative stress and NF-kappaB activation in late diabetic complications. Biofactors 10: 157-167, 1999

11. Fehrenbach H, Weiskirchen R, Kasper M and Gressner AM Up-regulated expression of the receptor for advanced glycation end products in cultured rat hepatic stellate cells during transdifferentiation to myofibroblasts. Hepatology 34: 943-952, 2001.

12. Brett J, Schmidt AM, Yan SD, et al: Survey of the distribution of a newly characterized receptor for advanced glycation end products in tissues. Am J Pathol 143: 1699-1712, 1993.

13. Lohwasser C, Neureiter D, Popov Y, Bauer M and Schuppan D: Role of the receptor for advanced glycation end products in hepatic fibrosis. World J Gastroenterol 15: 5789-5798, 2009.

14. Guimarães EL, Empsen C, Geerts A and van Grunsven LA Advanced glycation end products induce production of reactive oxygen species via the activation of NADPH oxidase in murine hepatic stellate cells. J Hepatol 52: 389-397, 2010.

15. Xia JR, Liu NF and Zhu NX: Specific siRNA targeting the receptor for advanced glycation end products inhibits experimental hepatic fibrosis in rats. Int J Mol Sci 9: 638-661, 2008.

16. Barouch $\mathrm{DH}$, Liu J, Li H, et al: Vaccine protection against acquisition of neutralization-resistant SIV challenges in rhesus monkeys. Nature 482: 89-93, 2012.

17. Desmet VJ: Knodell RG, Ishak KG, Black WC, Chen TS, Craig R, Kaplowitz N, Kiernan TW and Wollman J. Formulation and application of a numerical scoring system for assessing histological activity in asymptomatic chronic active hepatitis [Hepatology 1981;1:431-435]. J Hepatol 38: 382-386, 2003.

18. Ishak K, Baptista A, Bianchi L, et al: Histological grading and staging of chronic hepatitis. J Hepatol 22: 696-699, 1995.

19. Karin M and Lin A: NF-kappaB at the crossroads of life and death. Nat Immunol 3: 221-227, 2002.
20. Luo JL, Kamata $\mathrm{H}$ and Karin M: The anti-death machinery in IKK/NF-kappaB signaling. J Clin Immunol 25: 541-550, 2005.

21. Haskill S, Beg AA, Tompkins SM, et al: Characterization of an immediate-early gene induced in adherent monocytes that encodes I kappa B-like activity. Cell 65: 1281-1289, 1991.

22. Beg AA, Finco TS, Nantermet PV and Baldwin AS Jr: Tumor necrosis factor and interleukin-1 lead to phosphorylation and loss of I kappa B alpha: a mechanism for NF-kappa B activation. Mol Cell Biol 13: 3301-3310, 1993.

23. Aggarwal BB: Nuclear factor-kappaB: the enemy within. Cancer Cell 6: 203-208, 2004

24. Yan SD, Schmidt AM, Anderson GM, et al: Enhanced cellular oxidant stress by the interaction of advanced glycation end products with their receptors/binding proteins. J Biol Chem 269: 9889-9897, 1994

25. Yan SD, Stern D and Schmidt AM: What's the RAGE? The receptor for advanced glycation end products (RAGE) and the dark side of glucose. Eur J Clin Invest 27: 179-181, 1997.

26. Li J and Schmidt AM: Characterization and functional analysis of the promoter of RAGE, the receptor for advanced glycation end products. J Biol Chem 272: 16498-16506, 1997.

27. Hellerbrand C, Jobin C, Licato LL, Sartor RB and Brenner DA: Cytokines induce NF-kappaB in activated but not in quiescent rat hepatic stellate cells. Am J Physiol 275: G269-G278, 1998.

28. Hellerbrand, Wang SC, Tsukamoto H, Brenner DA and Rippe RA: Expression of intracellular adhesion molecule 1 by activated hepatic stellate cells. Hepatology 24: 670-676, 1996.

29. Liu C, Tao Q, Sun M, et al: Kupffer cells are associated with apoptosis, inflammation and fibrotic effects in hepatic fibrosis in rats. Lab Invest 90: 1805-1816, 2010.

30. Senoo H, Yoshikawa K, Morii M, Miura M, Imai K and Mezaki Y: Hepatic stellate cell (vitamin A-storing cell) and its relative - past, present and future. Cell Biol Int 34: 1247-1272, 2010.

31. Otogawa K, Ogawa T, Shiga R, Ikeda K and Kawada N: Induction of tropomyosin during hepatic stellate cell activation and the progression of liver fibrosis. Hepatol Int 3: 378-383, 2009. 